\title{
Improvement of energy utilization in natural gas liquid plant through using self-refrigeration system
}

\author{
H.Farzaneh , B.Abbasgholi \\ Science and Research Branch, Islamic Azad University, Tehran, Iran \\ * Corresponding author. Tel: +982144865320, Fax: +982144865003, E-mail: info@hfarzaneh.com
}

\begin{abstract}
In recent years, there has been great incentive to improve the energy utilization with which the existing capital in offshore and onshore surface facilities is utilized. One of the most energy intensive processes in oil upstream industry is natural gas liquid or NGL recovery plant. The main gorge of energy consumption in conventional NGL plants is propane refrigeration. Hence, more attention should be focused on the effective utilization of propane chillers in a NGL plant. In this study, a novel process configuration for recovery of natural gas liquids in NGL plant is purposed. The required refrigeration in this configuration is obtained by a selfrefrigeration system. In summary, the novel scheme generates refrigeration internally, decreasing cooling load of propane chiller and providing additional refrigeration for inlet gas cooling due to plant capacity increase. Besides, the recycled stripping gas also eliminates the need for external reboiler heat. The warmer the stripping gas, the less demand is placed upon the bottom reboiler, thereby saving fuel and energy cost. In this investigation, a simulation model has been developed on the basis of using novel configuration in Gachsaran NGL1200 in south of Iran. The model has been applied for evaluating of energy utilization in this plant. Results of the model show decreasing in total electricity demand of the plant from $268 \mathrm{kWh} / \mathrm{t}_{\mathrm{NGL}}$ to $175 \mathrm{kWh} / \mathrm{t}_{\mathrm{NGL}}$ by decreasing cooling load and electricity consumption in propane chiller. Also, the need for reboiler heat is satisfied and efficacy of demethanizer column is improved from $72 \%$ to $84 \%$ by more NGL recovery. Finally, economical analysis of the new retrofit has been studied.
\end{abstract}

Keywords: NGL plant, self-refrigeration, SGR, energy utilization

\section{Introduction}

Natural Liquid gas factories which produce NGL are one of the important and energy intensive units of offshore industries. In these units, natural gas liquids are separated from the sweet gas which has been sweetened in gas sweetening units before. Recovery of natural gas liquids (NGL) components in gas not only may be required for hydrocarbon dew point control in a natural gas stream, but also yields a source of revenue, e.g., natural gas may include up to about fifty percent by volume of heavier hydrocarbons recovered as NGL [1].

Most of the NGL plants in operation today use conventional single-stage turbo expander technology for moderately high ethane recovery. Based on this technology, after the inlet gas is treated to remove water and other contaminants, it's cooled by cold residue gas in gas/gas exchangers. Propane refrigeration is often required to help in condensing the heavy components for a rich gas. Then, liquid condensed from the inlet gas is separated and fed to the tower for further fractionation after being flashed to the tower pressure. The remaining non-condensed vapor portion is subject to turbo-expansion to the top section of the demethanizer column, with the cold liquids acting as the top reflux to enhance recovery of heavier hydrocarbon components.

The growing economic opportunities offered by the markets associated with natural gas liquids determined the development of using different technologies in NGL recovery units. The difference between the various technologies lays in the energy recovery strategies that each of them utilizes [2].

One of the most attractive technologies for reducing energy intensity in NGL recovery unit is Stripping Gas Refrigeration (SGR) method. SGR is a self-refrigeration system is widely 
applicable not only for new, grass-root plants but for revamping old, existing plants. This technology utilizes a slipstream from the demethanizer bottom. This stream is totally or partially vaporized, providing additional refrigeration for inlet gas cooling. The flashed vapor generated from the self-refrigeration cycle is recycled back to the column, where it serves as stripping gas. Stripping gas increases the critical pressure thus enhancing the relative volatility.

This paper focuses on revamping existing plants using the stripping gas refrigeration scheme. To this aim, factory of NGL 1200 in south of Iran is selected as case study. The results show the economic return on retrofit investment is much more attractive and also, there are opportunities for upgrading the performance of the plant, e.g., plant capacity increases and energy intensity decreases over the time [3].

\section{NGL recovery process}

The process flow diagram of a NGL plant based on the simulation of NGL1200 by HYSYS software is depicted in figure (1). According to this figure, inlet sweet gas flows into the two stages of gas to gas heat exchanging process $\left(E_{1}\right.$ and $\left.E_{3}\right)$ and exchanges its heat with separated gas stream form the three phases separator $\left(E_{6}\right)$ and therefore, its temperature is decreased from $65^{0 \mathrm{C}}$ to $25^{0 \mathrm{C}}$. Then, outflow stream from second heat exchanger enters into two stages of propane chilling system $\left(E_{4}\right.$ and $\left.E_{5}\right)$ and it is cooled to temperature lower than -29 centigrade degrees to condense out the liquids. At the exit point of chilling system, gas has two phases condition and therefore liquid and vapor phases should be separated by separator $\left(E_{6}\right)$. The vapor phase returns to the heat exchanger $\left(E_{3}\right)$ and the liquid phase is then fed into the demethanizer column which has 9 trays to stabilize gas liquids and separate light compounds. Demethanizer column also has a kettle reboiler for providing required heat in the bottom section of the column for vaporizing heavy product and recycling it to the column. Overhead flow of column which has more methane and ethane will be recompressed by compressor $\left(E_{11}\right)$ and will be returned to the gas injection unit; propane, butane and condensates are separated as bottom product and sent to the pressurized refrigerated storage vessels to await transportation to market [4].

Table (1) represents physical properties of streams which have been approximated by the Peng-Robinson equation of state formula through developing simulation model by HYSYS software. The aforementioned simulation model has been applied for analysis of performance of the factory of NGL1200 and estimation total energy intensity and efficiency of this plant [5].

According to results of simulation, total performance and energy intensity of NGL1200 are represented in table (2). Also, major energy intensive equipments of NGL1200 are reported in table (3). 


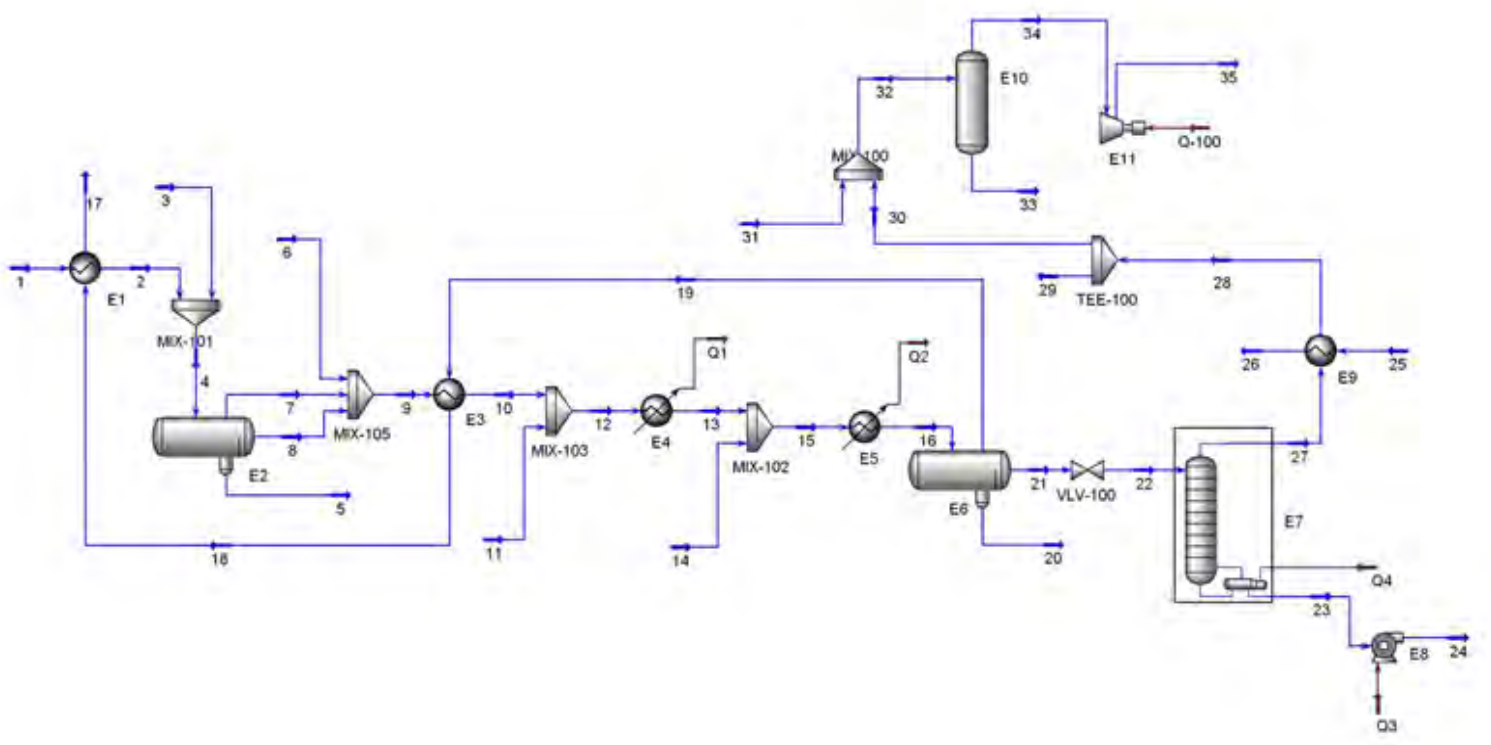

Fig. 1 Process flow diagram of NGL1200

\section{Self-refrigeration method}

Self- refrigeration method is a modern method to increase NGL plant capacity, to decrease plant electricity consumption and to eliminate the need for external reboiler load. Also, application of this method increases critical pressure and volatility of demethanizer column and therefore, efficacy of column will be improved. This method is known as Stripping Gas Refrigeration (SGR) method [6].

SGR method generates internal refrigeration by expanding a liquid stream from the bottom of the demethanizer column. Simulated process of SGR method and its application in NGL1200 is represented in figure (2). According to this figure, liquid stream from the bottom of the column (stream 39) is then heated by indirect heat exchange with inlet sweet gas to generate a two-phase stream. The two-phase stream (stream 42) is flashed in a separator. The flashed vapor (stream 44) is compressed and recycled to the demethanizer as a stripping gas, which increases the ethane and propane concentration in the column. The flashed liquid stream (stream 43) is pumped and mixed with other NGL product streams.

Three major advantages of using SGR method in a NGL plant may be concluded by following items [7]:

1) Increasing production level up to $20 \%$.

2) Increasing recovery of ethane. Concentration of ethane and propane will be increased in the column and heat profile on the trays will be decreased significantly.

3) Increasing operational pressure of the column is one of the other advantages of this method which increases volatility of propane and ethane and then separation efficacy of column will be increased.

Modification of physical properties of streams after using SGR method in NGL1300 is represented in table (4) [8]. 
Table1. Physical properties and flow rate of streams

\begin{tabular}{|c|c|c|c|c|c|c|c|}
\hline Stream line & 1 & 2 & 3 & 4 & 5 & 6 & 7 \\
\hline Temperature (C) & 60.5 & 37 & 62.1 & 38.3 & 38.3 & 25 & 38.3 \\
\hline Pressure $(\mathrm{kPa})$ & 3690 & 3680 & 3770 & 3680 & 3680 & 4300 & 3680 \\
\hline Mass flow (t/h) & 200.6 & 200.6 & 12.8 & 213.4 & 0.47 & 2.3 & 211.5 \\
\hline Stream line & 8 & 9 & 10 & 11 & 12 & 13 & 14 \\
\hline Temperature (C) & 38.3 & 38.3 & 24 & 25 & 24 & -5 & 25 \\
\hline Pressure $(\mathrm{kPa})$ & 3680 & 3680 & 3670 & 4300 & 4300 & 3655 & 4300 \\
\hline Mass flow (t/h) & 1.4 & 215.2 & 215.2 & 2.2 & 217.4 & 217.4 & 2.2 \\
\hline Stream line & 15 & 16 & 17 & 18 & 19 & 20 & 21 \\
\hline Temperature (C) & -5 & -29 & 47 & -10 & -29 & -29 & -29 \\
\hline Pressure $(\mathrm{kPa})$ & 3655 & 3640 & 3510 & 3640 & 3640 & 3640 & 3640 \\
\hline Mass flow (t/h) & 219.6 & 219.6 & 113 & 113 & 113 & 7 & 99.6 \\
\hline Stream line & 22 & 23 & 24 & 27 & & & \\
\hline Temperature (C) & -38 & 33.3 & 35 & -38 & & & \\
\hline Pressure $(\mathrm{kPa})$ & 2000 & 2000 & 3910 & 2000 & & & \\
\hline Mass flow (t/h) & 99.6 & 78 & 78 & 21.6 & & & \\
\hline
\end{tabular}

Table2. Performance and energy intensity of NGL1300

\begin{tabular}{lc}
\hline Inlet gas flow rate & $206 \mathrm{t} / \mathrm{h}$ \\
\hline NGL production & $78 \mathrm{t} / \mathrm{h}$ \\
\hline Lean gas production & $128 \mathrm{t} / \mathrm{h}$ \\
\hline Electricity intensity & $268.5 \mathrm{kWh} / \mathrm{t}$ \\
\hline Thermal heat intensity & $56.4 \mathrm{kWh} / \mathrm{t}$ \\
\hline Demethanizer Efficacy & $72 \%$ \\
\hline
\end{tabular}

Table3. Specification of energy intensive equipments of NGL1200

\begin{tabular}{lcc}
\hline & $\begin{array}{c}\text { Electrical power } \\
(\mathrm{kW})\end{array}$ & $\begin{array}{c}\text { Heat load } \\
(\mathrm{kW})\end{array}$ \\
\hline Propane pre chiller $\left(\mathrm{E}_{4}\right)$ & 3673 & 7014 \\
\hline Propane main chiller $\left(\mathrm{E}_{5}\right)$ & 3673 & 6153 \\
\hline Reboiler & - & 4411 \\
\hline Lean Gas Compressor & $531 \times 2$ & - \\
\hline
\end{tabular}

Table4. Physical properties of main streams after using SGR

\begin{tabular}{lccc}
\hline Stream line & $\begin{array}{c}\text { Flow rate } \\
\mathrm{t} / \mathrm{h}\end{array}$ & $\begin{array}{c}\text { Pressure } \\
\mathrm{kPa}\end{array}$ & $\begin{array}{c}\text { Temperature } \\
\mathrm{C}\end{array}$ \\
\hline $\begin{array}{l}\text { External gas line from } \\
\text { two phase heat exchanger (15) }\end{array}$ & 9 & 3650 & 7.7 \\
\hline $\begin{array}{l}\text { The last external line } \\
\text { from two phase heat exchanger (42) }\end{array}$ & 104 & 1900 & 16 \\
\hline $\begin{array}{l}\text { The last internal line to } \\
\text { two phase heat exchanger (39) }\end{array}$ & 104 & 2000 & -26 \\
\hline $\begin{array}{l}\text { External line from compressor } \\
\text { to demethanizer column(45) }\end{array}$ & 9 & 1900 & 16 \\
\hline
\end{tabular}




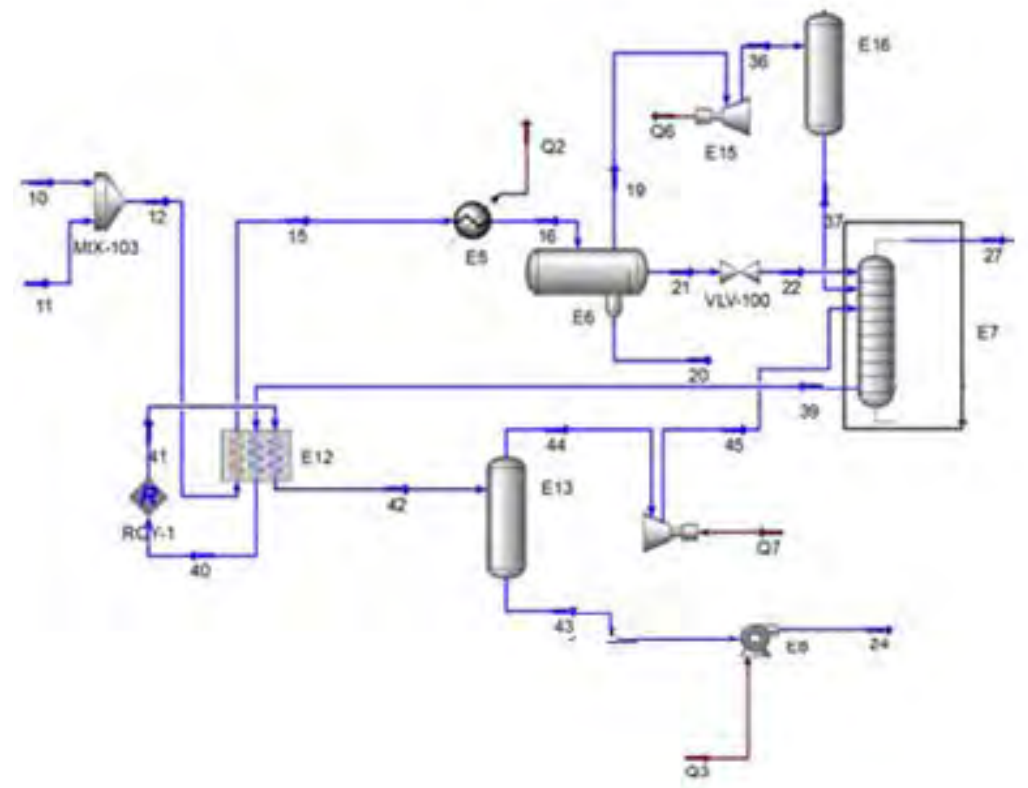

Fig. 2 Using SGR method in NGL1200

\section{Results and Discussions}

Comparison between results of simulation of NGL1200 before and after using SGR method is represented by table (5).

Table5. Comparison between obtained results before and after using SGR method

\begin{tabular}{lcc}
\hline & Before & After \\
\hline NGL production rate $(\mathrm{t} / \mathrm{h})$ & $78 \mathrm{t} / \mathrm{h}$ & 92.8 \\
\hline Electricity intensity $\left(\mathrm{kWh} / \mathrm{t}_{\mathrm{NGL}}\right)$ & 268.5 & 175 \\
\hline Thermal energy intensity $\left(\mathrm{kWh} / \mathrm{t}_{\mathrm{NGL}}\right)$ & 56.4 & 0 \\
\hline Demethanizer efficacy $(\%)$ & 72 & 84 \\
\hline
\end{tabular}

The results indicate that, application of self-refrigeration method reduces electricity intensity of the plant up to $34.7 \%$ and also eliminates the need for reboiler heat load completely. Decreasing in electricity intensity is obtained directly from replacing cooling load of propane per-chiller by heat exchanging of liquid stream from the bottom of demethanizer column with inlet sweet gas. Required capital investment for improving this novel configuration in Gachsaran NGL1200 is represented in table (6).

Table6. Capital investment of SGR method

\begin{tabular}{lc}
\hline \multicolumn{1}{c}{ Item } & Capital Investment $\left(10^{3} \$\right)$ \\
\hline Expander & 256 \\
\hline Separators & 21.6 \\
\hline Compressor & 25.6 \\
\hline Pump & 15 \\
\hline Two phase heat exchanger & 336 \\
\hline Installation & 182 \\
\hline
\end{tabular}


The results of feasibility study show payback period of total investment of project will be lower than 2 years when the unit price of electricity and NGL is considered consequently, 4 cent per kWh and 500 cent per kg [10].

\section{Conclusion}

The objective of this research work has been to introduce a novel configuration in NGL plants which is obtained by a self-refrigeration system name as Stripping Gas Refrigeration (SGR). SGR scheme provides overall energy integration and replaces propane refrigeration system. The main results of using this configuration may be concluded as decreasing propane refrigeration, eliminating external heat source of reboiler, decreasing compression hoarse power of the plant. Also, using this method is accompanied with lower capital and operating cost with less impact to the existing equipment of the plant. With purposing total capital investment around 836 thousands dollars including, net present value (NPV) of project may be estimated at 5.6 millions dollars through 15 years operation of the system and its economical feasibility will be supported [11].

\section{Acknowledgment}

We take this opportunity to thank Iranian Fuel Conservation Company for attending in this paper.

\section{References}

[1] J.Bibler, J.S.Marshall, C.Raymond, Status of worldwide coal mine methane emissions and use, International Journal of Coal Geology, 1998, pp.283-310

[2] B.Tirandazi, M.Mehrpooya, A.Vatani , Effect of the valve pressure drop in exergy analysis of $\mathrm{c}_{2}+$ recovery plants refrigeration cycle , International journal of electrical power and energy systems engineering, 2008, pp.4-8.

[3] L.Roger, J.Chen, Retrofit for NGL Recovery Performance Using a Novel Stripping Gas Refrigeration Schem, IPSIllc, Hostune, Texas USA, 2007

[4] W.C. Lyones, Standard Hand Book Of petroleum \& Natural Gas Engineering, Elsevier, 2007

[5] M.Kamaruddin A.Hamid, HYSYS An Introduction to Chemical Engineering Simulate, Department chemical engineering Maleysia,Thirth edition, 2006.

[6] G.Yao, J.J.Chen, S.Land , D.G.Elliot, Enhanced recovery process, 1999, patent 5,992,175.

[7] J.Lee, Y.Z.Jame, S.Y.Juh, D.G.Elliot, International refrigeration for enhanced NGl recovery, 2006, patent 150,627

[8] A. J. Kidnay, W. Parrish, Fundamental Natural Gas Processing, GPP.INC, 2006.

[9] W.County, N.Dakota, Natural gas engineering, McGraw-Hill, Second edition, 2007.

[10] A.J.Kinday, W. R.parrish , Fundamentals of natural gas processing , Taylor and Francis Group , Boca Raton, London, New York, 2006

[11] S.Peters, K.B.Time, R.West, Plant Design \&Economics For Chemical Engineering McGraw-Hill ,Forth edition, 2007. 